Randomized Control Trials

\title{
Regular insulin added to total parenteral nutrition vs subcutaneous glargine in non-critically ill diabetic inpatients, a multicenter randomized clinical trial: INSUPAR trial
}

\author{
Gabriel Olveira a, b, c, *, Jose Abuín a, b, Rafael López ${ }^{\mathrm{d}}$, Sandra Herranz ${ }^{\mathrm{e}}$,
}

Jose M. García-Almeida ${ }^{\mathrm{f}}$, Katherine García-Malpartida ${ }^{g}$, Mercedes Ferrer ${ }^{\mathrm{h}}$, Emilia Cancer ${ }^{\mathrm{i}}$, Luis M. Luengo-Pérez ${ }^{\mathrm{j}}$, Julia Álvarez ${ }^{\mathrm{k}}$, Carmen Aragón ${ }^{1}$, María J. Ocón ${ }^{\mathrm{m}}$, Álvaro García-Manzanares ${ }^{\mathrm{n}}$, Irene Bretón ${ }^{\circ}$, Pilar Serrano-Aguayo ${ }^{\mathrm{p}}$, Natalia Pérez-Ferre ${ }^{\mathrm{q}}$, Juan J. López-Gómez ${ }^{\mathrm{r}}$, Josefina Olivares ${ }^{\mathrm{s}}$, Carmen Arraiza ${ }^{\mathrm{t}}$, Cristina Tejera ${ }^{\mathrm{u}}$, Jorge D. Martín v , Sara García w, Ángel L. Abad ${ }^{\mathrm{x}}$, María R. Alhambra ${ }^{\mathrm{y}}$, Ana Zugasti ${ }^{\mathrm{z}}$, Juan Parra ${ }^{\text {aa }}$, Sara Torrejón ${ }^{\text {ab }}$, María J. Tapia ${ }^{a}$

a Unidad de Gestión Clínica de Endocrinología y Nutrición, Hospital Regional Universitario de Málaga, Instituto de Investigación Biomédica de Málaga (IBIMA), Spain

${ }^{\mathrm{b}}$ Universidad de Málaga, Spain

${ }^{c}$ CIBERDEM (CB07/08/0019), Instituto de Salud Carlos III, Madrid, Spain

d Servicio de Endocrinología y Nutrición, Hospital Universitari de Bellvitge, L'Hospitalet de Llobregat (Barcelona), Spain

e Servicio de Endocrinología y Nutrición, Hospital Universitario de Guadalajara, Guadalajara, Spain

${ }^{\mathrm{f}}$ Servicio de Endocrinología y Nutrición. Hospital Universitario Virgen de la Victoria, Málaga, Spain

${ }^{g}$ Servicio de Endocrinología y Nutrición, Hospital Universitario y Politécnico La Fe, Valencia, Spain

${ }^{\text {h }}$ Servicio de Endocrinología y Nutrición, Hospital Clínico Universitario Virgen de la Arrixaca, Murcia, Spain

i Sección de Endocrinología y Nutrición, Hospital Universitario de Fuenlabrada, Madrid, Spain

j Servicio de Endocrinología y Nutrición, Hospital Universitario de Badajoz, Badajoz, Spain

${ }^{\mathrm{k}}$ Servicio de Endocrinología y Nutrición, Hospital Universitario Príncipe de Asturias, Madrid, Spain

${ }^{1}$ Servicio de Endocrinología y Nutrición, Hospital Universitario Fundación Jiménez Díaz, Madrid, Spain

${ }^{\mathrm{m}}$ Servicio de Endocrinología y Nutrición, Hospital Universitario Lozano Blesa, Zaragoza, Spain

${ }^{\mathrm{n}}$ Servicio de Endocrinología y Nutrición, Hospital General La Mancha Centro, Alcázar de San Juan, Spain

- Servicio de Endocrinología y Nutrición, Hospital Universitario Gregorio Marañón, Madrid, Spain

${ }^{\mathrm{p}}$ Unidad de Endocrinología y Nutrición, Hospital Universitario Virgen del Rocío, Sevilla, Spain

${ }^{q}$ Servicio de Endocrinología y Nutrición, Hospital Clínico San Carlos, Madrid, Spain

${ }^{r}$ Servicio de Endocrinología y Nutrición, Hospital Clínico Universitario de Valladolid, Valladolid, Spain

${ }^{s}$ Servicio de Endocrinología y Nutrición, Hospital Universitario Son Llatzer, Illes Balears, Spain

${ }^{\mathrm{t}}$ Servicio de Endocrinología y Nutrición, Complejo Hospitalario de Jaén, Jaén, Spain

" Servicio de Endocrinología y Nutrición, Complejo Hospitalario Universitario de Ferrol, A Coruña, Spain

v Servicio de Endocrinología y Nutrición, Hospital Universitario Severo Ochoa, Leganés, Madrid, Spain

w Servicio de Endocrinología y Nutrición, Complejo Asistencial Universitario de León, León, Spain

x Unidad de Nutrición - Sección de Endocrinología, Hospital General Universitario de Alicante, Alicante, Spain

y Servicio de Endocrinología y Nutrición, Hospital Universitario Reina Sofía, Córdoba, Spain

${ }^{\mathrm{z}}$ Servicio de Endocrinología y Nutrición, Complejo Hospitalario de Navarra, Navarra, Spain

aa Servicio de Endocrinología y Nutrición, Hospital de Mérida, Badajoz, Spain

${ }^{\text {ab }}$ Servicio de Endocrinología y Nutrición, Hospital de Sant Joan Despí Moisès Broggi, Barcelona, Spain

\section{A R T I C L E I N F O}

Article history:

Received 18 January 2019

Accepted 20 February 2019

\section{S U M M A R Y}

Background: There is no established insulin regimen in T2DM patients receiving parenteral nutrition. Aims: To compare the effectiveness (metabolic control) and safety of two insulin regimens in patients with diabetes receiving TPN.

\footnotetext{
Abbreviations used: GI, Glargine Insulin; RI, Regular Insulin; SGA, Subjective Global Assessment; T2DM, Type 2 Diabetes Mellitus; TPN, Total Parenteral Nutrition.

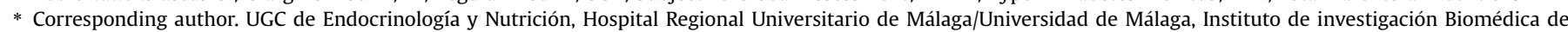
Málaga (IBIMA), Plaza del Hospital civil s/n, Málaga, 29007, Spain. Fax: +34 952286704.

E-mail addresses: gabrielm.olveira.sspa@juntadeandalucia.es, gabrielolveiracasa@gmail.com (G. Olveira).
} 
Keywords:

Non-critically ill patient

Diabetes

Insulin regimen

Glargine insulin

TPN
Design: Prospective, open-label, multicenter, clinical trial on adult inpatients with type 2 diabetes on a non-critical setting with indication for TPN. Patients were randomized on one of these two regimens: $100 \%$ of RI on TPN or $50 \%$ of Regular insulin added to TPN bag and $50 \%$ subcutaneous GI. Data were analyzed according to intention-to-treat principle.

Results: 81 patients were on RI and 80 on GI. No differences were observed in neither average total daily dose of insulin, programmed or correction, nor in capillary mean blood glucose during TPN infusion $(165.3 \pm 35.4$ in RI vs $172.5 \pm 43.6 \mathrm{mg} / \mathrm{dL}$ in $\mathrm{GI} ; p=0.25)$. Mean capillary glucose was significantly lower in the GI group within two days after TPN interruption $(160.3 \pm 45.1$ in RI vs $141.7 \pm 43.8 \mathrm{mg} / \mathrm{dL}$ in $\mathrm{GI}$; $p=0.024)$. The percentage of capillary glucose above $180 \mathrm{mg} / \mathrm{dL}$ was similar in both groups. The rate of capillary glucose $\leq 70 \mathrm{mg} / \mathrm{dL}$, the number of hypoglycemic episodes per 100 days of TPN, and the percentage of patients with non-severe hypoglycemia were significantly higher on GI group. No severe hypoglycemia was detected. No differences were observed in length of stay, infectious complications, or hospital mortality.

Conclusion: Effectiveness of both regimens was similar. GI group achieved better metabolic control after TPN interruption but non-severe hypoglycemia rate was higher in the GI group.

Clinical trial registry: This trial is registered at clinicaltrials.gov as NCT02706119.

(C) 2019 The Author(s). Published by Elsevier Ltd. This is an open access article under the CC BY-NC-ND license (http://creativecommons.org/licenses/by-nc-nd/4.0/).

\section{Introduction}

Diabetes mellitus has reached epidemic proportions in most parts of the world [1]. The estimated prevalence of diabetes in Spain is of $14 \%$ of the adult population [2]. The prevalence of type 2 diabetes mellitus in the hospital setting is also elevated, and in this case, it is associated with increases in mortality, hospital stay, and costs [3].

Prevalence of diabetes in patients who start total parenteral nutrition (TPN) to either treat or prevent malnutrition is also elevated [4]. Besides, the use of TPN is itself a risk factor for the onset or aggravation of hyperglycemia, regardless of a prior history of diabetes [5]. Values above $180 \mathrm{mg} / \mathrm{dL}$ are associated with a greater incidence of complications and death in hospitalized patients who receive parenteral nutrition [4,6]. Difficulty to reach an adequate metabolic control is higher in patients with diabetes mellitus who require parenteral nutrition when compared with patients with prediabetes or stress-induced hyperglycemia, despite receiving higher doses of insulin [7].

The best insulin regimen to use in these patients remains unknown, and few studies have examined the effectiveness and security of the regimens, especially in non-critically ill patients with type 2 diabetes [8-11].

The most prevailing regimen to control hyperglycemia is the introduction of regular insulin added to TPN bags and using subcutaneous Regular insulin as a correction $[7,10,12]$. This regimen has the advantage that it can deliver the insulin intravenously at a steady rate alongside carbohydrates, reducing the risk of hypoglycemia, and, in malnourished patients with lack of subcutaneous tissue, it may prevent the need for frequent insulin injections.

However other regimens have been proposed, on small scale studies, generally retrospective, including the subcutaneous administration of a long acting insulin such as Glargine [11,13-17], NPH [9], NPL [18], Degludec [19] or non-specified [20]. These new regimens based on long-acting insulins might achieve similar safety and metabolic control $[13,14]$ and, at least theoretically, could reduce glycemic variability, which has been associated with an increase in morbidity and mortality in patients on TPN [21], and facilitate the transition to basal-bolus hospital regimens once TPN is reduced or interrupted [22].

Nevertheless, only three randomized prospective studies have been published, all of them unicenter, small scale, and short studies; and none of those assessed blood glucose control after TPN interruption [13-15]. So new randomized, prospective, and multicenter studies that compare different insulin regimens in non-critically ill patients with diabetes who receive TPN with a higher number of patients and a longer monitoring period are required.

Our hypothesis is that two different insulin regimens (50\% Glargine insulin as basal component $+50 \%$ Regular insulin as nutritional component versus 100\% Regular insulin added to the TPN bag both as basal and nutritional component) could be equally effective and safe during TPN infusion.

The aim of the INSUPAR trial was to compare the effectiveness (metabolic control) and safety of 2 insulin regimens: with or without Glargine as basal insulin in non-critically ill patients with type 2 diabetes who are receiving TPN.

\section{Materials and methods}

This prospective randomized open-label study was carried out involving 26 centers in Spain (23 university hospitals and 3 nonuniversity hospitals). The study was approved by the Spanish Agency for the Regulation of Drug and Healthcare Products (EUDRACT 2015-003954-42), the Research Ethics Committee provincial of Málaga and of every hospital where the study took place, and registered at clinicaltrials.gov (NCT02706119).

\subsection{Patients}

The study included adult ( $>18$ years) hospitalized non-critically ill (i.e., patients in non-intensive care unit setting) type 2 diabetes patients who planned to start with TPN (considering it provides more than $70 \%$ of the estimated total energy expenditure using Harris-Benedict equation taking into account stress factor) for any cause for at least 5 days between June 2016 and March 2018.

Patients were excluded following these criteria: they were in intensive care units, were type 1 diabetes mellitus or post-total pancreatectomy diabetes, $<18$ years of age, pregnant, renal failure stage 3b o superior (glomerular filtration rate below $45 \mathrm{~mL} / \mathrm{min}$ ), or with intradialytic parenteral nutrition (Supplementary Table 1).

Patients were considered to have diabetes as assessed according to the international criteria [23]. Blood glucose levels were obtained from capillary and the same glucose meter was provided (Freestyle Optium; Abbott Diabetes Care Inc, Witney, Oxon, United Kingdom) to every center. Hypoglycemia was defined as blood 
glucose $\leq 70 \mathrm{mg} / \mathrm{dL}$ and clinically significant hypoglycemia as glucose values $<54 \mathrm{mg} / \mathrm{dL}$. Severe hypoglycemia was defined as being associated with severe cognitive impairment regardless of blood glucose level [16,24].

\subsection{Randomization and course}

Upon establishing the inclusion in the study and signing the informed consent, data of the patients were introduced by each investigator in an online case report form that allocated treatment arms to each patient.

Baseline data were recorded: demographic variables, diagnosis on admission, prior comorbidity (Charlson Comorbidity Index; anthropometric data (weight, height, BMI)); year of diagnosis of type 2 diabetes, and treatment modality, concomitant prescription of hyperglycemic drugs (steroids, somatostatin, tacrolimus or cyclosporine), and nutritional assessment by SGA.

The initial total insulin (between 0.2 and $0.5 \mathrm{UI} / \mathrm{kg}$ of actual body with scales of $0.1 \mathrm{UI} / \mathrm{kg}$ ) was estimated by the physician experience basing on blood glucose prior to the initialization of TPN, age, weight, previous treatment, glomerular filtration rate among others.

Eligible participants were randomized $1: 1$ to receive one of these two possible insulin regimens:

- Regular insulin group (RI): $100 \%$ of insulin requirements administered as Regular insulin (Actrapid HM; Novo Nordisk A/ $\mathrm{S}$, Bagsværd, Denmark) added to the bag of TPN as basal and nutritional component.

- Glargine insulin group (GI): $50 \%$ of insulin requirements administered as Regular insulin (Actrapid HM; Novo Nordisk A/ $\mathrm{S}$, Bagsværd, Denmark) as nutritional component added to the bag of TPN $+50 \%$ of insulin administered as subcutaneous Glargine insulin U100 as basal component (Lantus SoloStar; Sanofi-Aventis Deutschland GmbH, Frankfurt am Main, Germany or Abasaglar KwikPen; Eli Lilly Nederland B.V, Utrecht, Netherlands).

Blood glucose measurements were performed every six hours until the patient discontinued TPN or up to 15 days at most. We continued to monitor capillary glucose on days 1 and 2 after TPN was stopped.

Blood tests were obtained on day 1,5 and previous to the interruption of TPN or on day 15 of the study to measure plasma venous glucose. Glycated hemoglobin [25] was measured at day 1.

Adjustments in insulin dose were made according to a previously designed algorithm (Supplementary Fig. 1 \& Supplementary Table 2). In both groups, corrections were made subcutaneously with Regular insulin when capillary glucose was above $140 \mathrm{mg} / \mathrm{dL}$. Two-thirds of the total amount of correction insulin was added daily to the previous regimen: in the RI group 100\% to the TPN bag and in the GI group 50\% to the TPN bag and 50\% to the subcutaneous Glargine insulin. If capillary glucose was below $100 \mathrm{mg} / \mathrm{dL}$ insulin was lowered according to the above-mentioned algorithm.

\subsection{TPN prescription}

Total energy expenditure was estimated per Harris-Benedict equation [26] multiplied by a factor ranging between 1.1 and 1.4 in relation to the metabolic stress of the disease. We used actual weight or adjusted weight [27] if BMI was above $25 \mathrm{~kg} / \mathrm{m}^{2}$.

The TPN formulae in all hospitals were provided as a total nutrient admixture (' 3 in 1') solution containing carbohydrates, proteins, and lipids. All the TPN patients were seen daily by a member of the hospital Nutrition Unit, who made adjustments in accordance with international guidelines [28-31]. TPN was administered through a central venous line used only for this purpose.

\subsection{Outcome measures}

Primary endpoint: mean capillary glucose during TPN infusion up to 15 days maximum.

Secondary endpoint:

1) Percentage of capillary glucose above $180 \mathrm{mg} / \mathrm{dL}$.

2) Mean capillary glucose $48 \mathrm{~h}$ after TPN interruption.

3) Glycemic variability (standard deviation and variation coefficient of capillary glucose)

4) Rate of hypoglycemia, percentage of patients with hypoglycemia and percentage of capillary glucose below or equal to $70 \mathrm{mg} / \mathrm{dL}$.

5) Complications during hospitalization:

a) Non-catheter and catheter related bloodstream infections: they were identified as an elevated white blood cell count in addition to one or more of the following: positive blood cultures, chest $\mathrm{x}$-ray suggestive of pneumonia, positive urine culture, postoperative wound infection and use of antibiotics.

b) Length of stay

c) In-hospital mortality

\subsection{Statistical analysis}

Data analysis was performed using SPSS version 22.0 [32]. The Kolmogorov-Smirnov test was used to assess whether the variables were normally distributed or not. We carried out both intention-to-treat and per-protocol analysis. The hypothesis contrast between proportions was done using the $\chi^{2}$ test with Fisher's exact test, when necessary. Hypothesis contrast for continuous variables between groups used the $t$ test for variables that followed a normal distribution, and a non-parametric test (Mann-Whitney or Wilcoxon) for variables that did not conform to normal. Variables tested repeatedly over time (mean capillary glucose) were also analyzed using repeated measures multiple analysis of variance according to time and group. For all calculations, statistical significance was set at $\mathrm{p}<0.05$ for two-tails.

\subsection{Sample size}

To calculate sample size, we used previous data [7] about noncritically ill diabetic patients who achieved mean blood capillary glucose during PN infusion of $179 \pm 46 \mathrm{mg} / \mathrm{dL}$. To detect differences in mean metabolic control during PN infusion of $25 \mathrm{mg} / \mathrm{dL}$ between both groups (two tails) with a confidence interval of $95 \%$ and a power of $80 \%$, a sample of at least 104 patients is required (52 per group).

\section{Results}

\subsection{Sample}

2286 patients with TPN were initially assessed and finally 163 patients with type 2 diabetes were selected to participate and signed the informed consent but 2 of them did not start TPN (Supplementary Fig. 2). 12 patients did not achieve the expected 5 days of TPN.

No differences were observed in any of the baseline features comparing both groups (Table 1): age, gender, renal function, Charlson index, age at diagnosis of diabetes, rate of patients with insulin and other antidiabetic medications prior to admission (Supplementary Table 3), reason for admission, anthropometric parameters, HbA1c and PN formulae. 
Table 1

Patient and TPN baseline characteristics.

\begin{tabular}{|c|c|c|c|}
\hline Variable $^{a}$ & $\mathrm{RI}(N=80)$ & $\mathrm{GI}(N=81)$ & $P$ value \\
\hline$n$ & 80 & 81 & - \\
\hline Men (\%) & 71.3 & 65.4 & 0.154 \\
\hline Caucasians (\%) & 100 & 100 & - \\
\hline Age (years) & $71.2 \pm 10.8$ & $70.8 \pm 9.0$ & 0.127 \\
\hline $\begin{array}{l}\text { Glomerular filtration rate }(\mathrm{mL} / \\
\min )\end{array}$ & $99.2 \pm 44.6$ & $95.8 \pm 31.3$ & 0.580 \\
\hline Charlson index & $7.0 \pm 3.1$ & $6.6 \pm 2.8$ & 0.457 \\
\hline \multicolumn{4}{|l|}{ Type 2 diabetes mellitus } \\
\hline Duration (years) & $10.1 \pm 7.3$ & $12.2 \pm 8.5$ & 0.152 \\
\hline Age of diagnosis (years) & $61.1 \pm 11.3$ & $58.6 \pm 11.1$ & 0.158 \\
\hline Patients with insulin, $n(\%)$ & $25(32.1)$ & $21(25.9)$ & 0.394 \\
\hline Insulin units (UI/kg/day) & $0.33 \pm 0.86$ & $0.33 \pm 0.92$ & 0.930 \\
\hline Patients only with insulin, $\mathrm{n}(\%)$ & $4(5.0)$ & $7(8.6)$ & 0.360 \\
\hline $\begin{array}{l}\text { Patients only with non-insulin } \\
\text { hypoglycemic treatments, n } \\
(\%)\end{array}$ & $48(60.0)$ & $52(64.2)$ & 0.583 \\
\hline $\begin{array}{l}\text { Patients with any antidiabetic } \\
\text { drug, } \mathrm{n}(\%)\end{array}$ & $74(92.5)$ & $74(91.4)$ & 0.790 \\
\hline Patients only with diet, n (\%) & $6(7.5)$ & $7(8.6)$ & 0.990 \\
\hline \multicolumn{4}{|l|}{ Reason for admission } \\
\hline Surgical, $n(\%)$ & $44(55.0)$ & $40(49.4)$ & 0,745 \\
\hline Oncohematological & $22(27.5)$ & $27(33.8)$ & \\
\hline Medical & $14(17.5)$ & $13(16.3)$ & \\
\hline \multicolumn{4}{|l|}{ Anthropometric variables } \\
\hline Weight (kg) & $73.2 \pm 18.8$ & $72.1 \pm 14.1$ & 0.570 \\
\hline Usual weight (kg) & $79.2 \pm 19.8$ & $79.2 \pm 16.7$ & 0.445 \\
\hline Adjusted weight (kg) & $64.7 \pm 8.9$ & $65.1 \pm 8.9$ & 0.075 \\
\hline Height $(\mathrm{m})$ & $1.63 \pm 0.09$ & $1.64 \pm 0.09$ & 0.368 \\
\hline $\operatorname{BMI}\left(\mathrm{kg} / \mathrm{m}^{2}\right)$ & $27.6 \pm 6.5$ & $26.8 \pm 4.8$ & 0.204 \\
\hline Harris-Benedict (kcal/day) ${ }^{\mathrm{b}}$ & $1290.8 \pm 170.2$ & $1308.8 \pm 175.0$ & 0.656 \\
\hline $\begin{array}{l}\text { Estimated total energy } \\
\text { expenditure (kcal/day) }\end{array}$ & $1602.3 \pm 218.4$ & $1632.7 \pm 242.0$ & 0.375 \\
\hline \multicolumn{4}{|l|}{ Subjective global assessment } \\
\hline Well nourished, $n(\%)$ & $30(37.5)$ & $22(27.2)$ & 0.193 \\
\hline Moderate malnutrition, $n(\%)$ & $25(31.3)$ & $36(44.4)$ & \\
\hline Severe malnutrition, $n(\%)$ & $25(31.3)$ & $23(28.4)$ & \\
\hline \multicolumn{4}{|l|}{$\mathrm{HbA}_{1 \mathrm{c}}$} \\
\hline$\%$ & $6.6 \pm 1.0$ & $6.6 \pm 1.1$ & 0.456 \\
\hline $\mathrm{mmol} / \mathrm{mol}$ & $49.5 \pm 12.5$ & $48.2 \pm 11.4$ & 0.494 \\
\hline \multicolumn{4}{|l|}{ TPN characteristics } \\
\hline Days with TPN (days) & $9.7 \pm 6.8$ & $10.5 \pm 7.4$ & 0.883 \\
\hline $\begin{array}{l}\text { Mean daily carbohydrates in PN } \\
(\mathrm{g})\end{array}$ & $185.5 \pm 31.1$ & $188.3 \pm 31.9$ & 0.583 \\
\hline $\begin{array}{l}\text { Mean daily amino acids in PN } \\
(\mathrm{g})\end{array}$ & $80.7 \pm 13.3$ & $82.5 \pm 14.6$ & 0.652 \\
\hline Mean daily lipids in PN (g) & $57.0 \pm 11.4$ & $56.2 \pm 12.4$ & 0.709 \\
\hline $\begin{array}{l}\text { Mean daily carbohydrates in PN } \\
\left(\mathrm{g} / \mathrm{kg}^{\mathrm{b}}\right)\end{array}$ & $2.82 \pm 0.42$ & $2.84 \pm 0.44$ & 0.554 \\
\hline $\begin{array}{l}\text { Mean daily carbohydrates in } \\
\text { other fluids (g) }\end{array}$ & $2.87 \pm 6.9$ & $4.26 \pm 8.1$ & 0,156 \\
\hline $\begin{array}{l}\text { Mean daily amino acids in PN } \\
\left(\mathrm{g} / \mathrm{kg}^{\mathrm{b}}\right)\end{array}$ & $1.23 \pm 0.19$ & $1.24 \pm 0.18$ & 0.482 \\
\hline Mean daily lipids in $\mathrm{PN}\left(\mathrm{g} / \mathrm{kg}^{\mathrm{b}}\right)$ & $0.87 \pm 0.18$ & $0.85 \pm 0.19$ & 0.431 \\
\hline Mean daily kcal PN (kcal/day) & $1638.3 \pm 225.5$ & $1647.8 \pm 229.9$ & 0.980 \\
\hline $\begin{array}{l}\text { Total mean daily kcal PN }+ \text { in } \\
\text { other fluids (kcal/day) }\end{array}$ & $1659.9 \pm 237.2$ & $1674.7 \pm 243.9$ & 0.872 \\
\hline \multicolumn{4}{|l|}{ Hyperglycemic drugs } \\
\hline Corticosteroids, $n(\%)$ & $17(21.3)$ & $9(11.1)$ & 0.080 \\
\hline Tacrolimus, $n(\%)$ & $0(0.0)$ & $1(1.2)$ & 0.319 \\
\hline Somatostatin, $n(\%)$ & $7(8.8)$ & $5(6.2)$ & 0.534 \\
\hline $\begin{array}{l}\text { Any drug that induces } \\
\text { hyperglycemia }{ }^{c}, n(\%)\end{array}$ & $22(27.5)$ & $15(18.5)$ & 0.176 \\
\hline
\end{tabular}

a Values are mean \pm SD unless otherwise stated.

b We used actual weight or adjusted weight if BMI was above $25 \mathrm{~kg} / \mathrm{m}^{2}$.

c This includes the number of patients that were on any hyperglycemic drug; in the RI group there were two patients with both Corticosteroids and Somatostatin.

\subsection{Metabolic control}

No statistically significant differences were observed comparing mean values of different glycemic parameters (venous blood glucose, capillary glucose, glycemic variability parameters, total insulin and capillary glucose decrements) neither during TPN infusion nor on each day of the study (Supplementary Table 4). Using repeated measures multiple analysis of variance, we found significant differences in relation to time (a linear decrease) in both groups. No differences were observed between groups neither in mean capillary glucose nor in the descent of capillary glucose with respect to the first day.

There were statistically significant differences in the rate of capillary glucose $\leq 70 \mathrm{mg} / \mathrm{dL}$, the number of hypoglycemic episodes per 100 days of TPN and in the percentage of patients with nonsevere hypoglycemia (higher on GI) (Table 2). However, none of the groups had any severe hypoglycemia episodes.

Two days after the interruption of TPN, we observed significantly lower mean capillary glucose levels on GI group vs RI.

No other statistically significant differences were observed between the two groups regarding complications (Table 3 ).

When data were analyzed per-protocol (excluding 12 patients that did not reach 5 days of TPN) the variables were still statistically significant.

\section{Discussion}

Our study is the first multicenter randomized clinical trial that assesses the effectiveness and safety of two different modalities of insulin therapy in non-critically ill diabetic patients who receive PN with a long follow-up and a monitoring period following its interruption.

Both regimens (50\% Glargine insulin as basal component $+50 \%$ Regular insulin as nutritional component versus $100 \%$ Regular insulin added to the TPN bag both as basal and nutritional component) are equally effective to reach an adequate metabolic control during PN infusion.

Clinical practice guidelines and consensus statements recommend a target glucose range of $140-180 \mathrm{mg} / \mathrm{dL}$ for the majority of non-critically ill patients, but more stringent goals may be appropriate for selected patients if this can be achieved without significant low blood glucose events [8,33]. During PN mean total capillary glucose, glycemic variability, and insulin dose were similar in both groups without finding significant differences in any day (Supplementary Table 4). We did not find differences in the percentage of measurements above $180 \mathrm{mg} / \mathrm{dL}$, values that have been associated with an increase in morbidity and mortality [4,6,34], or from 100 to $180 \mathrm{mg} / \mathrm{dL}$. These results are in accordance to the previously published randomized studies which compared subcutaneous Glargine versus Regular insulin added to $\mathrm{PN}$ in people with diabetes $[13,14,35]$.

As well as other authors [14], we have observed a tendency to have higher capillary glucose in GI group during the first days of TPN (the goal of reaching mean capillary glucose below $180 \mathrm{mg} / \mathrm{dL}$ could only be reached after three days in GI. On the contrary, RI achieved it on the first day). Nonetheless, we did not observe differences in metabolic control at different moments of the day between groups. Metabolic control was significantly better in GI on the $48 \mathrm{~h}$ after the interruption of $\mathrm{PN}$; Glargine insulin pharmacodynamics, with a duration of action close to $24 \mathrm{~h}$, could explain this difference.

Mean glycemic control reached with both regimens was similar to the results published in other prospective studies in patients with diabetes and PN (Supplementary Table 4) [13,14] or mildly superior to the one achieved with insulin pumps [15]. Our results are clearly better than the ones obtained in patients with hyperglycemia treated only with subcutaneous insulin regimens (basal plus correction insulin regimen, with no insulin added to PN bag) $[17,20]$. Despite this, one third of the patients showed a percentage 
Table 2

Outcomes - metabolic control.

\begin{tabular}{|c|c|c|c|}
\hline Variable $^{a}$ & $\mathrm{RI}(n=80)$ & $\mathrm{GI}(n=81)$ & $P$ value \\
\hline \multicolumn{4}{|l|}{ Insulin } \\
\hline Mean total daily insulin (IU) & $44.2 \pm 25.3$ & $48.9 \pm 25.8$ & 0.412 \\
\hline Mean correction daily insulin (IU) & $9.9 \pm 8.0$ & $11.5 \pm 7.8$ & 0.113 \\
\hline Mean total daily insulin (IU/kg) & $0.62 \pm 0.32$ & $0.69 \pm 0.37$ & 0.321 \\
\hline Mean correction daily insulin (IU/kg) & $0.14 \pm 0.12$ & $0.16 \pm 0.1$ & 0.095 \\
\hline $\begin{array}{l}\text { Mean total daily insulin/10 g of } \\
\text { carbohydrates in TPN (IU) }\end{array}$ & $2.4 \pm 1.1$ & $2.6 \pm 1.4$ & 0.156 \\
\hline \multicolumn{4}{|l|}{ Mean capillary glucose } \\
\hline 08:00 h (mg/dL) & $163.4 \pm 36.1$ & $169.2 \pm 45.0$ & 0.374 \\
\hline $13: 00 \mathrm{~h}(\mathrm{mg} / \mathrm{dL})$ & $169.6 \pm 37.1$ & $178.5 \pm 46.9$ & 0.187 \\
\hline $20: 00 \mathrm{~h}(\mathrm{mg} / \mathrm{dL})$ & $167.6 \pm 38.3$ & $169.4 \pm 45.5$ & 0.795 \\
\hline $00: 00 \mathrm{~h}(\mathrm{mg} / \mathrm{dL})$ & $155.5 \pm 38.4$ & $167.9 \pm 47.0$ & 0.087 \\
\hline During TPN (mg/dL) & $165.3 \pm 35.4$ & $172.5 \pm 43.6$ & 0.250 \\
\hline $\begin{array}{l}\text { Mean post-TPN capillary blood glucose } \\
48 \mathrm{~h}(\mathrm{mg} / \mathrm{dL})\end{array}$ & $160.3 \pm 45.1$ & $141.7 \pm 43.8$ & 0.024 \\
\hline $\begin{array}{l}\text { Mean Day } 1 \text { post-TPN capillary glucose } \\
(\mathrm{mg} / \mathrm{dL})\end{array}$ & $161.3 \pm 47.7$ & $143.1 \pm 53.8$ & 0.054 \\
\hline $\begin{array}{l}\text { Mean Day } 2 \text { post-TPN capillary glucose } \\
(\mathrm{mg} / \mathrm{dL})\end{array}$ & $160.6 \pm 47.3$ & $143.3 \pm 39.8$ & 0.046 \\
\hline \multicolumn{4}{|l|}{ Hypoglycemic variables } \\
\hline $\begin{array}{l}\text { Number of patients with capillary } \\
\text { glucose } \leq 70 \mathrm{mg} / \mathrm{dL}, n(\%)\end{array}$ & $9(11.2 \%)$ & $22(27.2 \%)$ & 0.016 \\
\hline $\begin{array}{l}\text { Number of patients with capillary } \\
\text { glucose }<54 \mathrm{mg} / \mathrm{dL}, n(\%)\end{array}$ & $1(1.2 \%)$ & $7(8.8 \%)$ & 0.064 \\
\hline Number of severe hypoglycemia, $n(\%)$ & 0 & 0 & \\
\hline $\begin{array}{l}\text { Number of hypoglycemia events/100 } \\
\text { days of TPN }\end{array}$ & $1.9 \pm 6.1$ & $4.9 \pm 9.8$ & 0.015 \\
\hline \multicolumn{4}{|l|}{ Capillary glucose $\%{ }^{\mathrm{b}}$} \\
\hline$\leq 70 \mathrm{mg} / \mathrm{dL}(\%)$ & $0.8 \pm 3.0$ & $1.8 \pm 3.5$ & 0.011 \\
\hline $71-100 \mathrm{mg} / \mathrm{dL}(\%)$ & $7.5 \pm 10.4$ & $7.0 \pm 8.9$ & 0.913 \\
\hline $101-140 \mathrm{mg} / \mathrm{dL}(\%)$ & $29.2 \pm 20.3$ & $27.6 \pm 23.3$ & 0.430 \\
\hline $141-180 \mathrm{mg} / \mathrm{dL}(\%)$ & $29.8 \pm 16.1$ & $26.4 \pm 16.0$ & 0.163 \\
\hline $71-180 \mathrm{mg} / \mathrm{dL}(\%)$ & $66.7 \pm 27.7$ & $61.2 \pm 30.0$ & 0.227 \\
\hline$>180 \mathrm{mg} / \mathrm{dL}(\%)$ & $32.7 \pm 27.2$ & $37.2 \pm 30.5$ & 0.435 \\
\hline $\begin{array}{l}\text { Standard deviation of capillary glucose } \\
(\mathrm{mg} / \mathrm{dL})\end{array}$ & $40.4 \pm 16.0$ & $43.4 \pm 19.0$ & 0.292 \\
\hline $\begin{array}{l}\text { Variation coefficient of capillary glucose } \\
\text { (\%) }\end{array}$ & $24.5 \pm 8.1$ & $25.5 \pm 10.2$ & 0.570 \\
\hline
\end{tabular}

Bold signifies P-value below 0.05 ( $\mathrm{p}<0.05$ ).

a Values are mean \pm SD unless otherwise stated.

b Based on the total capillary glucose carried out during TPN infusion.

of measurements above $180 \mathrm{mg} / \mathrm{dL}$, results similar to those found by our group previously in people with diabetes [7].

The insulin regimen and monitoring system should also minimize glycemic variability [36], as it has been associated with increased hospital mortality during TPN but not in people with diabetes [21]. Both variation coefficient and standard deviation of capillary glucose were similar in both groups and with similar results to those published by other authors [14,15].

The number of hypoglycemic events was significantly higher in $\mathrm{GI}$, nevertheless, all of them were mild and none of them were severe.

Insulin added to TPN bag has the advantage that it can deliver the insulin intravenously at a steady rate alongside carbohydrates

Table 3

Outcomes - complications.

\begin{tabular}{llll}
\hline Variable $^{\mathrm{a}}$ & $\mathrm{RI}(N=80)$ & $\mathrm{GI}(N=81)$ & $P$ value \\
\hline Length of stay (days) & $31.1 \pm 26.0$ & $29.8 \pm 22.0$ & 0.870 \\
Mortality (n, \%) & $11(13.8)$ & $13(16.0)$ & 0.682 \\
Infectious complications & & & \\
CLASBI,$n(\%)$ & $12(15.0)$ & $76(5.0)$ & 0.078 \\
Sepsis, $n(\%)$ & $7(8.8)$ & $3(3.7)$ & 0.210 \\
Pneumonia, $n(\%)$ & $3(3.8)$ & $3(3.7)$ & 1.000 \\
Surgical site infection, $n(\%)$ & $8(10.0)$ & $5(6.3)$ & 0.564 \\
Urinary tract infection, $n(\%)$ & $1(1.3)$ & $4(4.9)$ & 0.367 \\
\hline
\end{tabular}

a Values are mean \pm SD unless otherwise stated

b Central line-associated bloodstream infections. reducing the risk of hypoglycemia [10]. In a previous study published by our group in non-critically ill patients with PN [37] the rate of low blood glucose events $(<70 \mathrm{mg} / \mathrm{dL}$ ) was clearly inferior (only 0.8 per 100 days of PN and occurred in $6.8 \%$ of the patients) to the one observed in our current study, especially in GI group (Supplementary Table 4); however only $21.6 \%$ of the assessed cases presented diabetes.

Hakeam et al. [14] were the only group describing a lower percentage (although non-significant) of hypoglycemic events in patients with diabetes and PN in Glargine group (5.7\%) versus Regular insulin added to PN (11.4\%); lesser duration of the study (only 6 days after randomization) might partially explain the differences. Li et al. [15], comparing subcutaneous Glargine versus subcutaneous continuous insulin infusions in patients with diabetes receiving PN, did not observe any severe hypoglycemia. Oghazian et al., in stable critically ill patients with diabetes, did observe a higher number of non-significant hypoglycemic events in Glargine group during a period of 3 days [13]. Neff and Ramos et al. $[17,20]$ described low blood glucose events in patients with PN and hyperglycemia treated only with subcutaneous insulin in $29 \%$ and $22 \%$ of the cases, respectively; sudden interruption of PN as well as higher duration of PN [20] could be some of the factors that increase the risk of hypoglycemia [37] in these patients. The percentage of hypoglycemia might reach up to $40 \%$ of the patients with PN and hyperglycemia treated with infused intravenous insulin [21].

We did not observe any differences in number of infectious complications, length of stay or mortality (Table 3 ).

Similar to hyperglycemia, hypoglycemia is associated with increased in-hospital mortality but the risk might be limited to patients with spontaneous hypoglycemia and not to patients with drug-associated hypoglycemia [38]. We did not observe differences in mortality, length of stay or other complications between groups, maybe because of the absence of severe hypoglycemia.

It is well established that an elevation in blood glucose is a risk factor for infection [39]. Unlike other authors [13,14] that only evaluated glycemic control, we have also assessed the incidence of infectious and non-infectious complications but we did not find any significant differences in any of these variables. Mortality was also evaluated and it was similar in both groups, these figures are in agreement with those previously published by us in subgroups of people with diabetes [4].

Our study is, among the others of its kind, the one with the largest number of patients recruited and the only one that is multicenter. Besides, it includes a very homogeneous sample of patients (all of them previously diagnosed with type 2 diabetes mellitus, none with stress hyperglycemia and with very similar composition of the TPN bags), it evaluates the use of insulin during 15 days of PN, it continues the follow-up $48 \mathrm{~h}$ after the interruption of the PN, and it also includes the assessment of complications.

However, there are some limitations. First of all, the recruitment was variable (from 1 to 15 patients) so the low recruitment of some centers might have affected the analysis. There is also the fact that we focus on non-critically ill patients with type 2 diabetes mellitus, therefore we cannot apply these conclusions to another group of patients; nevertheless we have chosen these patients because they are the most difficult ones to control in previously published studies [7]. Sample size was calculated to detect differences in mean capillary glucose but not in complications so the conclusions regarding complications should be taken cautiously. Besides, although we have made an ample number of statistical comparisons, the parameters that reach significance (hypoglycemic events and metabolic control after the interruption of PN) are concordant. And finally, of the 161 patients who started TPN, 12 of them did not reach 5 days of treatment, however, the results were still 
statistically significant as both intention-to-treat and per-protocol analysis.

In conclusion, we have observed that both regimens (50\% subcutaneous Glargine as basal component $+50 \%$ Regular insulin as nutritional component versus $100 \%$ Regular insulin added to total parenteral nutrition bag (basal and nutritional component)) are similar in relation to its effectiveness to achieve an adequate metabolic control during PN infusion in non-critically ill patients with diabetes so both regimens could be used. Nevertheless, GI group achieved better metabolic control after TPN interruption and non-severe hypoglycemia rate was higher in the GI group. These data indicate that in patients with 100\% Regular insulin added to TPN bag, Glargine may improve the transition and control after its interruption if it is prescribed previously [22].

This study opens the way for other clinical trials that might evaluate other insulin regimens and in other group of patients with hyperglycemia and PN.

\section{Sources of support}

This work was supported by Instituto de Salud Carlos III (ISCIII, co-funded by FEDER, EU, "Una manera de hacer Europa"), Ministerio de Ciencia, Innovación y Universidades, Gobierno de España (PI15/01034), and SAEDYN 2016 research project. CIBERDEM is an initiative of the Instituto de Salud Carlos III.

\section{Authors' contributions}

G.O. substantially contributed to the conception and design of the study, acquisition, analysis, and interpretation of the data; statistical analysis; and drafting of the manuscript. J.A. contributed to the acquisition, analysis, and interpretation of the data; statistical analysis; revised the article for important intellectual content and drafting of the manuscript. R.L., S.H., J.M.G.A, K.G., M.F., E.C., L.M.L.P, J.A., C.A., M.J.O., A.G.M., I.B., P.S.A., N.P.F., J.J.L.G., J.O., C.A., C.T., J.D.M., S.G., A.L.A., M.R.A., A.Z., J.P., and S.T. contributed to the data acquisition and critical review of the manuscript. M.J.T. substantially contributed to the design of the article; data acquisition; and critical review of the manuscript.

G.O. and J.A. are the guarantors of this work and, as such, had full access to all the data in the study and take responsibility for the integrity of the data and the accuracy of the data analysis.

\section{Conflict of interest}

No potential conflicts of interest relevant to this article were reported.

\section{Acknowledgements}

Parts of this study were presented in abstract form at $40^{\text {th }}$ Congress of the European Society of Parenteral and Enteral Nutrition, Madrid, Spain, 1-4 September 2018, and at the 59th Congress of the Spanish Society of Endocrinology and Nutrition, Barcelona, Spain, 18-20 October 2017.

We want to thank every patient who participated in the study and every member of the Study Group of Hyperglycemia in Parenteral Nutrition; Nutrition Area of the Spanish Society of Endocrinology and Nutrition (SEEN).

\section{Appendix A. Supplementary data}

Supplementary data to this article can be found online at https://doi.org/10.1016/j.clnu.2019.02.036.

\section{References}

[1] International Diabetes Federation. IDF diabetes atlas. 8th ed. Brussels, Belgium: International Diabetes Federation; 2017. p. 2017. http://www. diabetesatlas.org [accessed July 22, 2018].

[2] Soriguer F, Goday A, Bosch-Comas A, Bordiú E, Calle-Pascual A, Carmena R, et al. Prevalence of diabetes mellitus and impaired glucose regulation in Spain: the Di@betes Study. Diabetologia 2012;55:88-93. https://doi.org/ 10.1007/s00125-011-2336-9.

[3] Cheung NW, Napier B, Zaccaria C, Fletcher JP. Hyperglycemia is associated with adverse outcomes in patients receiving total parenteral nutrition. Diabetes Care 2005;28:2367-71.

[4] Olveira G, Tapia MJ, Ocón J, Cabrejas-Gómez C, Ballesteros-Pomar MD, VidalCasariego A, et al. Parenteral nutrition-associated hyperglycemia in noncritically ill inpatients increases the risk of in-hospital mortality (multicenter study). Diabetes Care 2013;36:1061-6. https://doi.org/10.2337/dc121379.

[5] McMahon MM, Nystrom E, Braunschweig C, Miles J, Compher C. American Society for Parenteral and Enteral Nutrition (A.S.P.E.N.) Board of Directors, et al. A.S.P.E.N. Clinical Guidelines. J Parenter Enteral Nutr 2013;37:23-36. https://doi.org/10.1177/0148607112452001.

[6] Pasquel FJ, Spiegelman R, McCauley M, Smiley D, Umpierrez D, Johnson R, et al. Hyperglycemia during total parenteral nutrition: an important marker of poor outcome and mortality in hospitalized patients. Diabetes Care 2010;33: 739-41. https://doi.org/10.2337/dc09-1748.

[7] Olveira G, Tapia MJ, Ocon J, Cabrejas-Gomez C, Ballesteros-Pomar MD, VidalCasariego A, et al. Prevalence of diabetes, prediabetes, and stress hyperglycemia: insulin therapy and metabolic control in patients on total parenteral nutrition (prospective multicenter study). Endocr Pract 2015;21:59-67. https://doi.org/10.4158/EP13441.OR.

[8] Olveira G, García-Luna PP, Pereira JL, Rebollo I, García-Almeida JM, Serrano P, et al. Recommendations of the GARIN group for managing non-critically ill patients with diabetes or stress hyperglycaemia and artificial nutrition. Nutr Hosp 2012;27:1837-49. https://doi.org/10.3305/nh.2012.27.6.6076.

[9] Jakoby MG, Nannapaneni N. An insulin protocol for management of hyperglycemia in patients receiving parenteral nutrition is superior to ad hoc management. J Parenter Enteral Nutr 2012;36:183-8. https://doi.org/ $10.1177 / 0148607111415628$.

[10] McCulloch A, Bansiya V, Woodward JM. Addition of insulin to parenteral nutrition for control of hyperglycemia. J Parenter Enteral Nutr 2017. https:// doi.org/10.1177/0148607117722750. 014860711772275.

[11] Umpierrez GE, Hellman R, Korytkowski MT, Kosiborod M, Maynard GA, Montori VM, et al. Management of hyperglycemia in hospitalized patients in non-critical care setting: an endocrine society clinical practice guideline. J Clin Endocrinol Metab 2012;97:16-38. https://doi.org/10.1210/jc.2011-2098.

[12] Hongsermeier T, Bistrian BR. Evaluation of a practical technique for determining insulin requirements in diabetic patients receiving total parenteral nutrition. J Parenter Enteral Nutr 1993;17:16-9. https://doi.org/10.1177/ 014860719301700116.

[13] Oghazian MB, Javadi MR, Radfar M, Torkamandi H, Sadeghi M, Hayatshahi A, et al. Effectiveness of regular versus glargine insulin in stable critical care patients receiving parenteral nutrition: a randomized controlled trial. Pharmacother J Hum Pharmacol Drug Ther 2015;35:148-57. https://doi.org/ 10.1002/phar.1546.

[14] Hakeam HA, Mulia HA, Azzam A, Amin T. Glargine insulin use versus continuous regular insulin in diabetic surgical noncritically ill patients receiving parenteral nutrition: randomized controlled study. J Parenter Enteral Nutr 2017;41:1110-8. https://doi.org/10.1177/0148607116644710.

[15] Li F, Zhang W, Liu B, Zhang D, Chen W, Yuan L, et al. Management of glycemic variation in diabetic patients receiving parenteral nutrition by continuous subcutaneous insulin infusion (CSII) therapy. Sci Rep 2018;8:5888. https:// doi.org/10.1038/s41598-018-24275-5.

[16] American Diabetes Association AD. 14. Diabetes care in the hospital: standards of medical care in diabetes-2018. Diabetes Care 2018;41:S144-51. https://doi.org/10.2337/dc18-S014.

[17] Ramos A, Rabasa F, Mendoza L, Cardenete J, Gill P, Morilla A, et al. Differences in glycemic control in diabetic and non-diabetic patients with parenteral nutrition using a basal plus correction insulin regimen: an observational, retrospective study. Diabetes Ther 2018. https://doi.org/10.1007/s13300-018-0433-1.

[18] Fatati G, Mirri E, Papi M, Coaccioli S. Use of neutral protamine lispro (NPL) insulin in a patient affected by acute pancreatitis under parenteral nutrition. Clin Ter 2011;162:231-4.

[19] Fatati G, Di Donato A, Grandone I, Menicocci P, Mirri E, Prosperini G, et al. Impact of insulin Degludec in hospitalized patients with and without type 2 diabetes requiring parenteral/enteral nutrition: an observational study. Adv Ther 2018. https://doi.org/10.1007/s12325-018-0709-X.

[20] Neff K, Donegan D, MacMahon J, O'Hanlon C, Keane N, Agha A, et al. Management of parenteral nutrition associated hyperglycaemia: a comparison of subcutaneous and intravenous insulin regimen. Ir Med J 2014;107:141-3.

[21] Farrokhi F, Chandra P, Smiley D, Pasquel F, Peng L, Newton C, et al. Glucose variability is an independent predictor of mortality in hospitalized patients treated with total parenteral nutrition. Endocr Pract 2014;20:41-5. https:// doi.org/10.4158/EP13131.OR. 
[22] Ramos A, Zapata L, Vera P, Betbese AJ, Pérez A. Transition from intravenous insulin to subcutaneous long-acting insulin in critical care patients on enteral or parenteral nutrition. Endocrinol Diabetes y Nutr 2017;64:552-6. https:// doi.org/10.1016/j.endinu.2017.08.005.

[23] American Diabetes Association AD. 2. Classification and diagnosis of diabetes: standards of medical care in diabetes-2018. Diabetes Care 2018;41:S13-27. https://doi.org/10.2337/dc18-S002.

[24] International Hypoglycaemia Study Group IHS. Glucose concentrations of less than $3.0 \mathrm{mmol} / \mathrm{L}(54 \mathrm{mg} / \mathrm{dL})$ should Be reported in clinical trials: a joint position statement of the American diabetes association and the european association for the study of diabetes. Diabetes Care 2017;40:155-7. https:// doi.org/10.2337/dc16-2215.

[25] Hanas R, John G. International HBA1c Consensus Committee O behalf of the IHC. 2010 consensus statement on the worldwide standardization of the hemoglobin A1C measurement. Diabetes Care 2010;33:1903-4. https:// doi.org/10.2337/dc10-0953.

[26] Roza AM, Shizgal HM. The Harris Benedict equation reevaluated: resting energy requirements and the body cell mass. Am J Clin Nutr 1984;40:168-82. https://doi.org/10.1093/ajen/40.1.168.

[27] Olveira G. Manual de Nutrición Clínica y Dietética. 3rd ed. 2016.

[28] Weimann A, Braga M, Carli F, Higashiguchi T, Hübner M, Klek S, et al. ESPEN guideline: clinical nutrition in surgery. 2017. https://doi.org/10.1016/ j.clnu.2017.02.013.

[29] Arends J, Bachmann P, Baracos V, Barthelemy N, Bertz H, Bozzetti F, et al. ESPEN guideline on nutrition in cancer patients*. 2016. https://doi.org/ 10.1016/j.clnu.2016.07.015.

[30] Gomes F, Schuetz P, Bounoure L, Austin P, Ballesteros-Pomar M, Cederholm T, et al. ESPEN guidelines on nutritional support for polymorbid internal medicine patients. 2017. https://doi.org/10.1016/j.clnu.2017.06.025.

[31] McClave SA, Taylor BE, Martindale RG, Warren MM, Johnson DR, Braunschweig $\mathrm{C}$, et al. Guidelines for the provision and assessment of nutrition support therapy in the adult critically ill patient. J Parenter Enteral Nutr 2016;40:159-211. https://doi.org/10.1177/0148607115621863.

[32] Released IBM Corp. IBM SPSS statistics for windows, version 22.0. Armonk, NY: IBM Corp; 2013.

[33] Moghissi ES, Korytkowski MT, DiNardo M, Einhorn D, Hellman R, Hirsch IB, et al. American association of clinical endocrinologists and American diabetes association consensus statement on inpatient glycemic control. Diabetes Care 2009;32:1119-31. https://doi.org/10.2337/dc09. 9029.

[34] Sarkisian S, Fenton TR, Shaheen AA, Raman M. Parenteral nutrition-associated hyperglycemia in noncritically ill inpatients is associated with higher mortality. Can J Gastroenterol 2010;24:453-7.

[35] Verçoza Viana M, Verçoza Viana L, Tavares AL, de Azevedo MJ. Insulin regimens to treat hyperglycemia in hospitalized patients on nutritional support: systematic review and meta-analyses. Ann Nutr Metab 2017;71:183-94. https://doi.org/10.1159/000481355.

[36] Corsino L, Dhatariya K, Umpierrez G. Management of diabetes and hyperglycemia in hospitalized patients. MDText.com, Inc.; 2000.

[37] Olveira G, Tapia MJ, Ocón J, Cabrejas-Gómez C, Ballesteros-Pomar MD, VidalCasariego A, et al. Hypoglycemia in noncritically ill patients receiving total parenteral nutrition: a multicenter study. (Study group on the problem of hyperglycemia in parenteral nutrition; nutrition area of the Spanish Society of Endocrinology and Nutrition). Nutrition 2015;31:58-63. https://doi.org 10.1016/j.nut.2014.04.023.

[38] Boucai L, Southern WN, Zonszein J. Hypoglycemia-associated mortality is no drug-associated but linked to comorbidities. Am J Med 2011;124:1028-35. https://doi.org/10.1016/j.amjmed.2011.07.011.

[39] Critchley JA, Carey IM, Harris T, DeWilde S, Hosking FJ, Cook DG. Glycemic control and risk of infections among people with type 1 or type 2 diabetes in a large primary care cohort study. Diabetes Care 2018;41:2127-35. https:// doi.org/10.2337/dc18-0287. 